\title{
Addressing the Conceptual Controversy of Sustainable Intensification of Agriculture: A Combined Perspective from Environmental Philosophy and Agri-Environmental Sciences
}

\author{
Gustavo Cambareri ${ }^{1, *}$ and Joshua Grant-Young ${ }^{2}$ \\ 1 Agrometeorology Group, Balcarce Research Station, INTA (Instituto Nacional de Tecnologia Agropecuaria), \\ Ruta Nacional 226 km 73.5, Balcarce 7620, Argentina \\ 2 Philosophy Department, College of Arts, University of Guelph, Guelph, ON N1G 2W1, Canada; \\ jgrantyo@uoguelph.ca \\ * Correspondence: cambareri.gustavo@inta.gob.ar; Tel.: +54-2266-439100
}

Received: 26 September 2018; Accepted: 13 November 2018; Published: 19 November 2018

\begin{abstract}
During the last 20 years, agronomists, environmentalists and related researchers have conveyed the need of producing enough food to satisfy the growing population demand, with minimum environmental footprint. Under this framework, the need for a "sustainable intensification" (SI) of agriculture has arisen, being a concept deeply contested the last several years. We aim to shed some light on the matter from the point of view of both environmental philosophy and agri-environmental sciences. We found that the lack of clarity exposes the conceptual limits of SI, since its attributions are far from being extrapolated, for example, to animal production. Agricultural science should ensure that stakeholders understand the facts and implications of SI before implementing them. In addition, if understood only as either a set of practices or a sort of panacea, SI will be closer to fail for stakeholders' expectations. Then, a key concern we have highlighted is one which should compel agri-environmental scientists and environmental philosophers alike to hold such conceptual frameworks accountable. Ensuring communities and public actors make informed choices about food security requires that shared goals between our disciplines are enacted in research, with community well-being as a core consideration of any debate regarding sustainability.
\end{abstract}

Keywords: sustainable intensification; agriculture; environmental philosophy; agri-environmental sciences; sustainability

\section{Introduction}

Pressure on agroecosystems as food-suppliers is consistently increasing, leading to the agri-food system satisfying the food demand through agriculture intensification [1], and, at the same time, raising concerns about the effects of agricultural intensification on the environment, such as agricultural greenhouse gases (GHG) emissions and losses in biodiversity [2]. Such trade-off has put the agriculture at a crucial decision point about the future path to follow for reaching global sustainability [3]. This is reflected in agricultural studies trends over the last 20 years, where agronomists, environmentalists and related researchers have conveyed the need for producing enough food to satisfy the growing population demand, without producing a significant environmental footprint [4]. Among these trends, "sustainable intensification" (SI) is a concept that has been deeply contested the last several years, triggering a controversy among agricultural scientists. The term SI was first mentioned by Raintree and Warner [5] in 1986 as a goal to achieve for agroforestry and, henceforth, has been gradually gaining supporters among scholars, being widely used in agriculture. However, it was not until nearly 10 years 
later when a more concrete definition was given about SI, identifying it as a type of agriculture that sought to maximize productivity and, at the same time, to reduce environmental damage through the combined action of low inputs, integrated management of soil nutrients, water, pests and local farmers' knowledge [6]. Nevertheless, the limits of the concept are not fully clear under this definition, since many points are common with agroecology [7] and ecological intensification [8], which leads to asking the question, what makes SI different to the other visions of agriculture? A hint was given by the Royal Society in the booklet "Reaping the Benefits: Science and the Sustainable Intensification of Global Agriculture" [9], where, rather than defined, SI is claimed to be a natural output of having a clear definition of sustainable agricultural systems. Furthermore, in this very booklet, SI was associated with the decrease and mitigation of greenhouse gases (GHG) emitted from agriculture. However, regardless of the abundance of hints and definitions, the idea is not easy to deliver, given that many studies contested SI as an oxymoron [10,11], or as controversial if it is also applied for cattle management [12]. Perhaps the more accurate approach to define SI was that given by Kuyper and Struik [13], where SI was contrasted to ecological intensification (EI) through using the dichotomy "Utopians" (SI supporters) vs. "Arcadians" (EI supporters). Such dichotomy allowed for making remarks about differences in, for example, philosophy, model, scale, and capital employed for either vision of agriculture. Then, if SI had to be defined through these differences, a possible sophisticated definition of SI for the current time would be that of an approach that prioritizes the sustainability of the agricultural business through specialization of agriculture, intensification of capital, science-based technology, and including the consideration of negative externalities such as GHG emissions and loss of biodiversity, resulting in economically sustainable and environment-friendly food production strategies. However, as it will be discussed further on, the problems of clarity and the underlying values of SI are obstacles not easy to overcome.

The main argumentation on behalf of SI states that there are multiple interpretations of what "sustainability" is and what "intensity" is $[4,14]$. On one hand, the term sustainability has been approached from an economic, environmental, productive and political point of view [15], though all the visions aim for the perennity of natural resources for sustaining the current and future use. On the other hand, some studies refer to grain yield and fertilization rate as valid indicators of intensity for the agricultural system [16,17]. Then, there is indeed a contradiction between the rationale of SI and the two words used to define it. From an epistemological point of view, "sustainable" does not match properly with "intensification" due to remarks about the perception of perennial agricultural intensification, with no limits in the definition for input addition to croplands, making it hard for the term not being framed under a market-driven approach. This lack of conceptual limits for SI is similar to what was opportunely criticized by Suárez [18] in the term 'sustainable development', where the absence of explicit limits for 'development' in the definition, revealed that the dichotomy human development vs. nature conservation could not be easily solved by this term. In that sense, Pretty and Bharucha [4] suggested that some interpretations of SI may be weakened or strengthened according to the type of argumentation used to support the criticism. Given this context, we aim to bring new conceptual elements to the contestation of SI, revealing the point of view of environmental philosophy and underpinning some aspects of agri-environmental sciences usually underplayed by literature.

\section{SI Rationale Enlightened by Environmental Philosophy}

Environmental philosophy is a useful tool for interrogating the utility of a concept like SI, since it involves social and political thought, ethics and applied sciences such as biology and ecology. A perennial concern within the field is finding compelling answers to questions such as "why do/should I care about this natural resource" and "what should be done to preserve a natural resource?" Our first concern about SI is that the answers to the mentioned questions are unsatisfactorily met by the current SI's rationale.

When applied sciences and philosophy interact, the latter can act as a useful tool by unravelling unexplored assumptions held in relation to a practice or issue of concern and reason about the 
implications of our ideas and decisions. If we take the example preceding this and consider what "should be done to preserve x", a colleague might ask "why do we care about $x$ is this case?" Are we to preserve $\mathrm{x}$ for its own sake, or for some use it provides to the community (or an ecosystem)? Should we choose one over the other, we need compelling reasons that we can give to justify this choice. While agricultural sciences can give us the facts on the ground, environmental philosophy can motivate reflection concerning the value judgements, ethical problems and claims we wish to make about how we might act.

\subsection{Considering Claims, Values and Audiences}

Prior to addressing problems in defining SI, it is philosophically important to address two issues: what types of claims do SI proponents make when advocating such a position, and what role does value play in SI?

First, it is helpful to distinguish between descriptive and normative claims [19] and their importance in this case. A descriptive claim is one that declares that the contents of said claim are the case and contain no judgement on values. In contrast, a normative claim asserts the contents of said claim ought to be the case and will contain a value judgment within. For example, if one were to use a forest as the focus of these two types of claims, a descriptive claim could be "The forest spans $x$ acres" while a normative claim could be "We should not permit logging in this forest".

Environmental philosophy treats these two types of claims as important guides for dealing with a variety of issues related to biodiversity, sustainability or animal welfare. Descriptive claims, often with the aid of scientific scholarship, can help us determine facts about the 'what it is' and can helpfully guide discussion on issues of policy. Normative claims have their place as well: though one might not always agree with the implications or assertions of an argument, it is important to know the value judgements that inform perspectives on an issue. These types of claims often seek to give grounds for why a stakeholder might perform some action (e.g., a moral justification for not logging in an area due to its intrinsic value or the effect it might have on an ecosystem's function).

Following from this, it is also helpful to distinguish between two concepts of value often explored in environmental philosophy: intrinsic value and instrumental value [20]. Intrinsic value seeks to establish the worth of an object not based on its usefulness for humans but rather independently of human needs or desires. An object, on this account, has an independent value for its own sake (e.g., environmental thought of points to an environment's naturalness or pristine qualities). In contrast, instrumental value often considers the value of an object in relation to the way it benefits a community (e.g., a cattle's creation of dairy products for human consumption, a landscape's ability to provide considerable space and suitable conditions for higher crop yields). Therefore, our suggestion is that a lack of clear commitment to a conception of value might also aid in bolstering the conception that SI is a 'contradiction' in terms.

A further consideration worth addressing is a distinction between intrinsic and instrumental value in relation to biodiversity. Environmental ethics aids scientific research and practice in articulating questions regarding the value of ecosystems and their constituent parts. Intrinsic value is one conceptual framework which has significant purchase (notably, from the United Nations Convention on Biological Diversity, which explicitly endorses the idea that biodiversity on the whole is intrinsically valuable). Though it presents a potentially laudable premise that damaging ecosystems or their constituents presents a harm beyond any effect on the goals of humans, it also creates concerns in terms of how one wishes to parse connections between scientific practice (SI) and environmental ethics on the ground [21].

One issue is that, whether one considers ecosystem services or the individual parts of an ecosystem, conceptions of value may rely on instrumental value judgements. A human agent may argue $x$ species of tree or $y$ service is valuable because they deem it to be something they desire or consider a utilitarian calculation concerning an ecosystem service that benefits a maximal population. The 'demand' value of individual species or services can often be cast in terms of human needs (resources, medicines, food). 
For conservation biology, biodiversity is often (though not exclusively) cast in terms of how various properties in systems render said systems dependable producers of ecosystem services. In short, we often think about value in terms of what we perceive an individual/group/system's value is to humans.

In thinking about animals, the conservation of species might present a particular problem in terms of intrinsic valuation. A practical example of such a concern might go as follows: in the process of implementing SI initiatives, it is determined that a portion of land adjacent to a farm is to be allotted to be used for agricultural purposes. On this land, a small population of a species of mammal exist that are not endangered, provide little in terms of direct production of ecosystem services and may only provide some aesthetic value for adjacent human populations. In fact, some neighboring species of animals may very well flourish should this population be moved or perish. As such, we can say that, instrumentally, the potential loss of this population of mammals might be (on a demand-value instrumentalist account) not entirely concerning - their presence is not integral to an ecosystem (or its services) and it provides little benefit to human populations. However, as is the case for many animal advocacy groups concerned with wildlife welfare broadly applied, the intrinsic value of this species demands that this population (no matter the number) should be preserved-regardless of human or nonhuman instrumental value.

What is one to do in this case? One answer SI might provide is a demand-value response, which suggests that, if the population's disappearance causes only direct harm to this small population, while providing greater benefit for human populations (e.g., allowing further development of agricultural land for feeding communities) and nonhumans alike, then it seems reasonable that moving this population or allowing it to perish would not be a considerable ethical concern. However, this may draw considerable ire from animal activists who would deem the intrinsic value of said species and its individual members as a potential justification to cease further agricultural development. That this population may not provide any apparent instrumental value is of no concern: the value of this population is, in itself, accepted as an unquestioned good.

Certainly, such a case of conflicting conception of values might also map onto animals involved in SI initiatives-particularly those raised for human consumption. While these animals may be argued to have several instrumental benefits for human populations, warranting at least some general principles of welfare (e.g., care geared towards disease prevention), animal activists who hold to an intrinsic conception of value would argue that even agricultural animals (e.g., cattle) have a value independent of human concerns-justifying greater ethical consideration beyond welfare.

Finally, for any discipline proposing practical solutions to everyday issues, it is important that stakeholders grasp effectively the methods and outcomes. In a socially-minded philosophical inquiry, a frequent concern in policy formulation is that the public misunderstands what certain policy is, along with the ways it will affect their communities (for better and for worse). Crucially, when we consider the application of SI initiatives outside of the Global North, the stakes for communities when information or practices are miscommunicated are high. As we will discuss later, the stakeholders in such a situation may not simply be disadvantaged-it may affect economic and food security for entire populations.

Then, our concern, stemming from problems of definition, is that, even if certain agricultural scientists advocating SI understand the functions and implications of this approach, the failure to make various aspects of it comprehensible leaves it not only to skepticism from colleagues, but does a few favors for those who seek to benefit from such an approach.

\subsection{Defining Terms: Problems of Clarity}

The purpose of such efforts is to aid in determining, in addition to defining a concept, what claims relate to such a definition and the implications of said claims. A particularly useful article by Garnett et al. [12] engages in such labor clearly depicting that "to articulate a more sophisticated definition of SI, one which clarifies the logic on which it rests and the context and conditions within which it 
should be implemented". Thus, acknowledging SI as an 'evolving concept' whose definition and motivations are open to dispute, it seems prudent to revisit this article as a helpful tool for exploring SI on a philosophical account.

Furthermore, Garnett et al. [12] highlight four premises upon which SI operates: (1) the need to increase production of food for ameliorating food insecurity, (2) said increased production must come via higher yields-cautious of the concern that increasing agricultural land use "carries major environmental costs" (e.g., loss of biodiversity, potential negative effects on ecosystem services, proliferation of GHG emissions), (3) a goal of balancing increased productivity with environmental sustainability-with an emphasis on "context-and-location specific" rather than universal solutions, and (4) flexibility in techniques to achieve the prior premises. SI as an agricultural science concept, then, can be situated within a discourse of how the yield of arable crops and foodstuff might be increased to meet global demand, aware of concerns regarding food insecurity, environmental health, and external issues of resource use and scarcity.

Despite efforts to clarify what SI conceptually means, critics still contest its use. The debate arises from the weak efficacy of the concept as defined by proponents of SI, as noted by Mahon et al. [11]. The latter authors also emphasize that multiplicity of interpretations regarding "indicators, rationale, scale, and farm type" produces considerable skepticism about SI's utility as a concept from detractors. Mahon et al. [11] demonstrate that indicators invoked in literature related to SI often demonstrate a lack of clarity or detail in their employment of various terms.

An example of the potential concern for conceptual clarity in indicators left open to interpretation revolves around the implementation of subsidies (a 'governance indicator') related to SI. Mahon et al. [11] note that there is considerable debate about the application of subsidies and their benefits or detriments. Certainly, reflecting on stakeholders, it is prudent to consider that subsidies represent one avenue or a 'tool' for improving agricultural production yields and services rendered to stakeholders, as well as a means to soften economic hardship-particularly in the context of the Global South. However, it is also identified that subsidies may compromise market competitiveness in developed nations, exacerbate imbalances between land-owners and tenant farmers and (crucial to discussions of sustainability) potentially promote 'unsustainable' or 'wasteful' practices.

What is important in this example, Mahon et al. [11] note, is that, in invoking subsidies as a positive governance indicator, SI advocates appear to be avoiding various criticisms noted and merely focusing on data preferential to casting subsidies as a positive indicator-taking it as a given that subsidies are solely to be understood in beneficial terms, while ignoring any detrimental results of implementation. Such an effort, the authors suggest, should be met with skepticism. If the implementation of subsidies results in economic imbalances between land-owner and tenant, particularly in economically depressed areas in the Global North or South, a myriad of concerns (from labor dispute to further exacerbation of food insecurity) may arise. Furthermore, since SI contends to seek sustainability in relation to any effort to increase yield, the potential for promoting wasteful practices stemming from subsidies seems crucial to recognize. Not doing so invites skepticism about the ethical commitments as well as scientific practices tied to SI.

Given the context-specific approach promoted by SI, the authors would agree with Mahon et al. [11] that greater care should be taken to identify what subsidies aim to accomplish (simply, the problems they wish to solve) and in what context such subsidies are proposed to be used.

A clear difficulty persisting within literature expounding the beneficial implementation of SI efforts is, then, the continued absence of the 'sophisticated definition' of terms which Garnett et al. [12] advocate for. This was also elucidated by Struik et al. [14], who see in SI a process of societal negotiation rather than a set of specific practices. From a philosophical account, this presents a serious concern: if the terms giving a normative argument to SI cannot be adequately defined, how could SI be defended adequately against critics or even explained effectively to non-academic audiences (e.g., agricultural workers, activists, local stakeholders, policy makers)? A final consideration in this aspect is the glaring lack of engagement with various "social impacts of their adoption". The scarcity with which issues 
of equity, food sovereignty or environmental degradation are adequately treated within literature affirming the potential efficacy of SI signals a serious problem. Chiefly, when one considers the aforementioned case of subsidies (presenting only positive data concerning their application), this does a considerable injustice not only in terms of communicating the science and product of SI, it places communities (particularly in the Global South) in a precarious position of trusting that (as stakeholders in any SI venture) their communities will benefit from SI. Echoing Mahon et al. [11] contentions, if these indicators are not adequately defined and concerns unsatisfactorily engaged, can such efforts be properly considered 'sustainable'? With little elucidation on such matters, disagreement on indicator efficacy in literature and disputes between stakeholders about methods and goals of implementation, the normative thrust for any implementation of SI remains murky at present.

\subsection{Assessing Goals through Value: Further Concerns}

Some questions of value exist concerning the balance of animal welfare and environmentalist concerns with the prescribed goals of SI. In terms of parsing some middle ground between concerns, problems persist beyond definition. Garnett et al. [12] reasonably point to a tension existing between concerns for welfare and the term 'intensification'. Welfare can cut both ways: one might find some forms of increased animal production to be efficaciously functional in terms of health (e.g., issues of disease), yet ethical and functional concerns exist regarding methods of selective breeding, ethical treatment and overconsumption [22]. Furthermore, when one confronts more stringent forms of animal advocacy beyond considerations of welfare (here, advocates of animal rights or abolitionism), philosophical arguments for the intrinsic value of animal lives or ameliorating suffering from a utilitarian perspective provide a spirited opposition to intensive animal farming. Given a lack of clarity concerning SI's approach to animal welfare, and further concerns regarding the environmental degradation tied to various practices of intensive animal farming, a clearer stance is needed beyond vague normative declarations on welfare issues raised here. What 'welfare' means for SI and what practices are best suited to its implementation are both required to aid in definition, but to buttress any normative support for SI, it seems reasonable to call advocates to formulate strong defenses of the welfare practices they deem suitable for the sake of clarity and to answer criticisms effectively.

Concerning intrinsic value, the commitment to sustainability of surrounding lands and protections against environmental degradation, one should ask: and for whose sake? Environmentalists who uphold an intrinsic value argument for species or environments will no doubt question the murky commitments of SI to sustainability and also the ability for 'intensification' to satisfactorily safeguard the intrinsic value of surrounding environments and their inhabitants. While commitments to sustainability are articulated within SI's normative goals, SI advocates should work diligently to make a stronger justification for their conception of environmental practices and their implications. Otherwise, pressure from environmental activists, suspicious of the seriousness of commitments to sustainability, will likely persist [23].

\subsection{Making Things Clear for Stakeholders}

A closing consideration requires us to return to the social implications of SI. The 'social impacts of adoption' mentioned earlier prompted us to consider the level of adequate communication of the science and impacts of SI are being communicated beyond academic discussion. It seems prudent, looking beyond academic skepticism concerning the science and premises of SI, for future researchers to consider speaking directly with communities who have considered the implementation of SI initiatives. Greater attentiveness to the direct impact of SI initiatives on stakeholders, their context-specific concerns and research regarding how the public is informed about SI initiatives can be fruitful directions for identifying and measuring both stakeholder comprehension of SI initiatives and the impacts of SI on communities.

Equity and food justice are both concerns that scholars and agriculturalists alike have, and, in decades to come, must concern themselves with. If SI purports to offer solutions to such issues, 
which (as discussed prior) have lacked considerable clarity for even academics, how can the public be sure these solutions will be adequate for feeding future generations? We suggest that a greater communicative effort is required on the part of SI advocates to make explicit not only the claims and terms which they employ but ensure attentiveness to social impacts of SI.

If there is a benefit to SI's focus on context-specificity, it should lie in the effort of advocates of SI to actively engage the public (as well as effectively collaborate with state agents and NGOs) about the science and initiatives involved in intensification, as well as their commitment to sustainability. Given that the latter has been a source of contention between SI advocates and activists opposing SI initiatives, a helpful addition to framing the commitment to context-specificity is educating the public concerning the practical implications of SI [23].

Communication need not only focus on education of the public: communication, for the authors, also means that advocates should work to learn the values and concerns of communities. Goals for such an endeavor might be as simple as identifying where intersections might lie between the goals of communities and those of SI, what aspects of their approach need more adequate communicative effort and how to meet the needs of communities on the ground.

Lastly, a social implication of this discussion that is less obvious (but nonetheless important) is the issue of public trust in science. SI presents initiatives such as seeking a mean between sustainability and food security, goals that (if satisfied) can be beneficial to communities across the world. In this spirit, SI should consider greater communicative efforts as crucial to cultivating not only trust in the scientific community but highlighting how SI can meet a communities' specific needs. Leshner [24] of the AAAS, in an editorial for Science, provides a closing consideration for thinking about the need to engage the public better in explaining beneficial scientific practices:

"There is no shortage of topics where policy-makers or other members of the public seem to persistently misunderstand, misrepresent or disregard the underlying science: climate change, genetically modified foods, vaccines or evolution, among others ... Public understanding of science not only affects people's ability to appreciate and make full use of the products of science, it also contributes to the extent of support for the scientific community ..."

Agricultural science, which provides considerable innovation and beneficial practices which feed countless humans, should ensure that stakeholders understand the facts and implications of SI before implementing them. Furthermore, consultation with stakeholders can be helpful in identifying context-specific needs for a community and build trust (as well as social capital, per Mahon et al.) between stakeholders and SI practitioners as the latter can identify what 'products of science' might better meet the former's needs, continued support for scientific endeavors, as well as the wellbeing of communities, depend on the informed public - not those left to uncertainty or misrepresentation.

\section{Agri-Environmental Considerations}

Leaving aside the philosophical concerns, there are agri-environmental aspects of SI that need to be addressed to come to this sophisticated definition. A key thoughtful process is to acknowledge that SI should be not a set of practices and recommendations but rather an analytical framework, with a certain degree of plasticity for different societies, institutions and managements [14]. It must be also mentioned that, for SI to succeed as a paradigm, an effort must be performed to build strong and substantial evidence about its benefits on GHG mitigation and low impact on biodiversity [3]. Although the studies about SI have increased the last several years, strong evidence about its overall benefits about GHG mitigation and biodiversity conservation is still missing, since SI implementation is very context-sensitive [25], so that the normative claims expressed above still cannot be fully satisfied.

To help to satisfy our concerns, and advance towards the sophisticated definition, the agrienvironmental aspect is essential to properly defining SI or even discarding it as a valid approach. Agri-environmental sciences address both the physical factors affecting food production and the externalities of the food system causing an environmental impact. Physical factors such as temperature, air humidity and precipitation affect food production through the shortening of growing seasons, 
extreme events such as flooding or drought, threatening food security [3]), which is and will be enhanced under the context of Climate Change, with negative effects on grain yield, food prices and child nutrition [26]. Although agriculture is part of both the problem and the solution regarding Climate Change [26], potential "solutions" such as SI cannot be only addressed from the point of view of food increase assuming a 'ceterus paribus' [14]. Loos et al. [27] suggest that increasing food production does not necessarily imply satisfaction of the needs of those that are more food insecure; rather, SI may result in disproportionate influence of the financial sector on the food market, through an impact of food prices. In addition, although Godfray and Garnett [28] remark that the current view and perception of SI is related to the increase of grain yield, they acknowledge that the concept needs an improvement when related to animal production, since it is frequently associated with "factory farming", having implications on animal welfare but also on the net income. In that regard, the dairy sector in Argentina is a paradigmatic example of how intensification can be economically unsustainable if not accompanied along with supporting policies for stakeholders, since around $3.6 \%$ of dairy farms went out of business during the period 2008-2016 [29]. Undoubtedly, in this example, the lack of engagement between "sustainable" and "intensification" prevails as pointed out by Loos et al. [27]. Regardless of the criticisms, many recent studies about SI reflect the efforts to re-define SI rationale $[25,27,28,30]$. Attempting to solve the mentioned inconsistencies, Weltin et al. [25] frame the SI under four fields of action: agronomic development, resource use efficiency, land use allocation and regional integration, concluding that "little effort is devoted to study SI as an objective requiring integrated practices, coupling the farm and landscape scales and different fields of action". Thus, the level of intensification attained during each stage in the transition to SI must allow the economic and environmental sustainability, beyond conceiving intensification as the only response to meet the global populational growth needs [28].

It is true that, if understood only as either a set of practices or a sort of panacea, SI will be closer to failing to meet the stakeholders' expectations. However, even if the notion of SI as goal-oriented is attained, it must be mentioned that either "sustainable" or "intensification" will have a short perennity once system stability is accomplished, since, as shown by the Argentinean example, countries' economic shortcomings might dampen stakeholder's investments, even achieving a high input efficiency. Therefore, not rationale but terminology must be polished and modified, due to at least a couple of reasons. On one hand, when assessing SI, Loos et al. [27] state that there is an inappropriate terminology and that the term can be easily undermined at the point of reducing it to a meaningless catch phrase, with weaknesses in both theoretical rigor and capability to guide to sustainability. On the other hand, technical, scientific evidence and farmer's choice converge not explicitly in what was properly noted by Struik et al. [14]: SI should be viewed as a coupled process of intensification-de-intensification (I/D), since, as a variable of interest intensifies (e.g., tonnes of grain per unit of natural resource, capital per unit of land, net income per unit of land, GHG emissions per unit of land), another must necessarily de-intensify (e.g., workforce per unit of land, biodiversity expressed as the number of wild vegetable and animal species per unit of surface), in spite of the gains in efficiency for the agricultural system (litters of water per tonne of grain, nitrogen consumed per tonne of grain, etc.). Environmental science has produced useful indicators that reflect some aspects of this trade-off such as carbon footprint [31], hydric footprint [32], and GHG emissions intensity [33]); in some studies, GHG intensity has been used for evaluating agricultural practices [34,35]) or for life cycle assessments [36]). Under the context of SI, keeping GHG intensity low would mean increasing grain yields through maximizing inputs' use efficiency; however, this may not always be the case when agro-climatic risk is taken into account, since even a low GHG emission during cropping season can be intensified when grain yield is severely affected by weather. Furthermore, market-driven intensification may paradoxically lead to a de-intensification of capital in future years if the harvest fails due to climatic adversities such as heat stress, frost or flooding. Then, the materialization of SI understood as a set of practices, whereas viewing it holistically seems quite idealistic [37]. Its weakness only lies in the word "intensification". 
As Schimel [38] has pointed out in his book "Writing Science": selecting words to coin terms is not a trivial task and above all is not easy. In the case of "intensification", the word seems to have too much emotional weight, drawing all the attention of readers/audiences, and subsequently hiding the idea one wants to convey. Then, a rhetorical question may be formulated twisting the words backwards in SI: are not we scientists looking for a "intensified sustainability" instead? This is because, as we said earlier, "intensification" has a short perenniality-reach, which will be given either by the physical limits of the environment or by how close the system is to being economically sustainable, whatever comes first. It is true that word meanings change as time advances, and etymological fallacies may be committed when compared with the original meaning as occurred, for example, with "agroecology" [39]. Another issue is that "intensification" is still very associated with "agricultural intensification" [4], as proved by the fact that the original definition [6] could not change the deeply rooted perception about "intensification". Hence, perhaps exchanging the term "intensification" by "transformation", which is also less ambitious, would lead to a better result regarding feasibility to convey the idea. Another useful insight would be considering SI as a path of transition towards sustainability, a sort of enviro-friendly intensification. Therefore, we suggest that the word "intensification" should be re-thought and properly supported by the lacking sophisticated definition, since, as discussed above, premises such as "satisfying the growing populational demand", "increasing animal welfare" and "attaining economic and environmental sustainability of farms" are easily arguable and can hardly resist well-argued criticisms. Otherwise, "intensification" may likely be replaced by other terms accordingly.

Finally, Foley et al. [1] give some clues about how to face the issue of increasing demand of food and malnourishment of human population without falling in the narrative of "intensifying the food system for good"; in agreement with our contentions, the authors comment on the importance of the ratio production: economic and environmental costs, the need for building resilience for the food system, and the principle of technology neutrality to improve crop performance. Additionally, Foley et al. [1] consider closing the grain yield gap as one out of many solutions to cope with the Malthusian predictions, suggesting that this hypothetical solution was appropriate for regions such as Africa, Latin America and Eastern Europe. Cassidy et al. [40] add the allocation of calories produced per hectare to this discussion (food vs. feed vs. biofuels), suggesting that, if the current crops cultivated worldwide were exclusively grown for food, the availability of calories for human nourishment would increase by $70 \%$. However, Loos et al. [27] disagree with the premise of increasing food as a meaningful solution, suggesting that a better and amplified focus should be on distributive and procedural justice. These different visions of food security reflect the Global North/South divide, and the rise of the participation agenda as described by Sumberg et al. [41] who contextualized the changes in the agronomy and agricultural policies during the last four decades. This context may be modifying the perceptions of SI as well, with interpretations closer to Foley et al. 's [1] vision in the North and closer to Loos et al.'s [27] in the South. Finally, Foley et al. 's [1] and Loos et al.'s [27] approaches converge in those solutions towards global sustainability not being rooted in a single view, so that SI must allow other insights to aid in achieving such a goal.

\section{Final Considerations}

Agri-environmental science and environmental philosophy share several interdisciplinary goals: proposing rigour in conceptual definitions, providing substantial evidence to confirm the premises of any framework (whether analytic or holistic in orientation) and ensuring communication of such concepts or frameworks and their yields to colleagues, practitioners or stakeholders within the public is clear and effective.

Regarding agricultural workers and the stakeholder communities who rely on their labor, the ability to implement beneficial practices and meet population needs requires advocates of SI to effectively communicate principles and goals. A key concern we have highlighted-feeding communities-is one which should compel agri-environmental scientists and environmental philosophers alike to hold such conceptual frameworks accountable. Ensuring communities and 
public actors make informed choices about food security requires shared goals between our disciplines are enacted in research, with community well-being as a core consideration of any debate regarding sustainability.

Funding: This research was supported by the authors' personal resources and no external funding was involved. Conflicts of Interest: The authors declare no conflict of interest.

\section{References}

1. Foley, J.A.; Ramankutty, N.; Brauman, K.A.; Cassidy, E.S.; Gerber, J.S.; Johnston, M.; Mueller, N.D.; O'Connell, C.; Ray, D.K.; West, P.C.; et al. Solutions for a cultivated planet. Nature 2011, 478, 337-342. [CrossRef] [PubMed]

2. Lal, R. Climate Change and Agriculture. In Climate Change: Observed Impacts on Planet Earth; Lechter, T., Ed.; Elsevier: Amsterdam, The Netherlands, 2016; 635p, pp. 465-489.

3. Lipper, L.; Thornton, P.; Campbell, B.M.; Baedeker, T.; Braimoh, A.; Bwalya, M.; Caron, P.; Cattaneo, A.; Garrity, D.; Henry, K.; et al. Climate-smart agriculture for food security. Nat. Clim. Chang. 2014, 4, 1068. [CrossRef]

4. Pretty, J.; Bharucha, Z.P. Sustainable intensification in agricultural systems. Ann. Bot. 2014, 114, 1571-1596. [CrossRef] [PubMed]

5. Raintree, J.B.; Warner, K. Agroforestry pathways for the intensification of shifting cultivation. Agrofor. Syst. 1986, 4, 39-54. [CrossRef]

6. Pretty, J.N. The sustainable intensification of agriculture. In Natural Resources Forum; Blackwell Publishing Ltd.: Oxford, UK, 1997; Volume 21, pp. 247-256.

7. Altieri, M.A. Agroecology: A new research and development paradigm for world agriculture. Agric. Ecosyst. Environ. 1989, 27, 37-46. [CrossRef]

8. Tittonell, P. Ecological intensification of agriculture-Sustainable by nature. Curr. Opin. Environ. Sustain. 2014, 8, 53-61. [CrossRef]

9. Baulcombe, D.; Crute, I.; Davies, B.; Dunwell, J.; Gale, M.; Jones, J.; Pretty, J.; Sutherland, W.; Toulmin, C. Reaping the Benefits: Science and the Sustainable Intensification of Global Agriculture; The Royal Society: London, UK, 2009.

10. Lang, T.; Barling, D. Food security and food sustainability: Reformulating the debate. Geogr. J. 2012, 178, 313-326. [CrossRef]

11. Mahon, N.; Crute, I.; Simmons, E.; Islam, M.M. Sustainable intensification—“Oxymoron” or "third-way"? A systematic review. Ecol. Indic. 2017, 74, 73-97. [CrossRef]

12. Garnett, T.; Appleby, M.C.; Balmford, A.; Bateman, I.J.; Benton, T.G.; Bloomer, P.; Burlingame, B.; Dawkins, M.; Dolan, L.; Fraser, D.; et al. Sustainable intensification in agriculture: Premises and policies. Science 2013, 341,33-34. [CrossRef] [PubMed]

13. Kuyper, T.W.; Struik, P.C. Epilogue: Global food security, rhetoric, and the sustainable intensification debate. Curr. Opin. Environ. Sustain. 2014, 8, 71-79. [CrossRef]

14. Struik, P.C.; Kuyper, T.W.; Brussaard, L.; Leeuwis, C. Deconstructing and unpacking scientific controversies in intensification and sustainability: Why the tensions in concepts and values? Curr. Opin. Environ. Sustain. 2014, 8, 80-88. [CrossRef]

15. Kuhlman, T.; Farrington, J. What is sustainability? Sustainability 2010, 2, 3436-3448. [CrossRef]

16. Tilman, D.; Balzer, C.; Hill, J.; Befort, B.L. Global food demand and the sustainable intensification of agriculture. Proc. Natl. Acad. Sci. USA 2011, 108, 20260-20264. [CrossRef] [PubMed]

17. Carlson, K.M.; Gerber, J.S.; Mueller, N.D.; Herrero, M.; MacDonald, G.K.; Brauman, K.A.; Havlik, P.; O'Connell, C.S.; Johnson, J.A.; Saatchi, S.; et al. Greenhouse gas emissions intensity of global croplands. Nat. Clim. Chang. 2017, 7, 63-68. [CrossRef]

18. Suárez, E. La falacia del desarrollo sustentable. Polémika 2010, 5.

19. Kornblith, H. Précis of knowledge and its place in nature. Philos. Phenomenol. Res. 2005, 71, 399-402. [CrossRef]

20. Justus, J.; Colyvan, M.; Regan, H.; Maguire, L. Buying into conservation: Intrinsic versus instrumental value. Trends Ecol. Evol. 2009, 24, 187-191. [CrossRef] [PubMed] 
21. Maclaurin, J.; Sterelny, K. What is Biodiversity? University of Chicago Press: Chicago, IL, USA, 2008.

22. Regan, T. Empty Cages: Facing the Challenge of Animal Rights; Rowman \& Littlefield: Lanham, MD, USA, 2004.

23. Friends of Earth International. Food and farming: Time to Choose! 2004. Available online: https:/ / www. foei.org/wp-content/uploads/2014/08/DEF-english.pdf (accessed on 5 August 2018).

24. Leshner, A. Capably Communicating Science. Science 2012, 337, 777. [CrossRef] [PubMed]

25. Weltin, M.; Zasada, I.; Piorr, A.; Debolini, M.; Geniaux, G.; Perez, O.M.; Scherer, L.; Marco, L.T.; Schulp, C.J. Conceptualising fields of action for sustainable intensification-A systematic literature review and application to regional case studies. Agric. Ecosyst. Environ. 2018, 257, 68-80. [CrossRef]

26. Smith, P.; Gregory, P.J. Climate change and sustainable food production. Proc. Nutr. Soc. 2013, 72, 21-28. [CrossRef] [PubMed]

27. Loos, J.; Abson, D.J.; Chappell, M.J.; Hanspach, J.; Mikulcak, F.; Tichit, M.; Fischer, J. Putting meaning back into "sustainable intensification". Front. Ecol. Environ. 2014, 12, 356-361. [CrossRef]

28. Godfray, H.C.J.; Garnett, T. Food security and sustainable intensification. Philos. Trans. R. Soc. B 2014, 369, 20120273. [CrossRef] [PubMed]

29. Servicio Nacional de Sanidad y Calidad Agroalimentaria (SENASA). Bovino y Bubalinos. Available online: https: / / www.argentina.gob.ar/senasa/mercados-y-estadisticas/estadisticas/animal-estadisticas / bovinos / bovinos-y-bubalinos-sector-primario (accessed on 20 August 2018).

30. Campbell, B.M.; Thornton, P.; Zougmoré, R.; Van Asten, P.; Lipper, L. Sustainable intensification: What is its role in climate smart agriculture? Curr. Opin. Environ. Sustain. 2014, 8, 39-43. [CrossRef]

31. Wiedmann, T.; Minx, J. A definition of 'carbon footprint'. Ecol. Econ. Res. Trends 2008, 1, 1-11.

32. Chapagain, A.; Hoekstra, A. Water Footprints of Nations; Value of Water Research Report Series No. 16; UNESCO-IHE: Delft, The Netherlands, 2004. Available online: http:/ / www.waterfootprint.org/Reports / Report16.pdf/ (accessed on 10 August 2018).

33. Hillman, T.; Ramaswami, A. Greenhouse gas emission footprints and energy use benchmarks for eight US cities. Environ. Sci. Technol. 2010, 44, 1902-1910. [CrossRef] [PubMed]

34. Venterea, R.T.; Maharjan, B.; Dolan, M.S. Fertilizer source and tillage effects on yield-scaled nitrous oxide emissions in a corn cropping system. J. Environ. Qual. 2011, 40, 1521-1531. [CrossRef] [PubMed]

35. Chen, X.; Cui, Z.; Fan, M.; Vitousek, P.; Zhao, M.; Ma, W.; Wang, Z.; Zhang, W.; Yan, X.; Yang, J.; et al. Producing more grain with lower environmental costs. Nature 2014, 514, 486-489. [CrossRef] [PubMed]

36. Jayasundara, S.; Wagner-Riddle, C. Greenhouse gas emissions intensity of Ontario milk production in 2014, 2011 compared with 1991. Can. J. Anim. Sci. 2014, 94, 155-173. [CrossRef]

37. Crist, E.; Mora, C.; Engelman, R. The interaction of human population, food production, and biodiversity protection. Science 2017, 356, 260-264. [CrossRef] [PubMed]

38. Schimel, J. Writing Science: How to Write Papers That Get Cited and Proposals That Get Funded; OUP USA: Cary, NC, USA, 2012; 222p.

39. Wezel, A.; Soldat, V. A quantitative and qualitative historical analysis of the scientific discipline of agroecology. Int. J. Agric. Sustain. 2009, 7, 3-18. [CrossRef]

40. Cassidy, E.; West, P.; Gerber, J.; Foley, J. Redefining agricultural yields: From tonnes to people nourished per hectare. Environ. Res. Lett. 2013, 8, 034015. [CrossRef]

41. Sumberg, J.; Thompson, J.; Woodhouse, P. Why agronomy in the developing world has become contentious. Agric. Hum. Values 2013, 30, 71-83. [CrossRef]

(C) 2018 by the authors. Licensee MDPI, Basel, Switzerland. This article is an open access article distributed under the terms and conditions of the Creative Commons Attribution (CC BY) license (http://creativecommons.org/licenses/by/4.0/). 